\title{
EFFECTIVENESS OF FORAY 48B OVER TIME AFTER APPLICATION AGAINST THE PAINTED APPLE MOTH
}

\author{
J.G. CHARLES, D.J. ALLAN, A. CHHAGAN and L.E. JAMIESON \\ HortResearch, Private Bag 92 169, Auckland, New Zealand \\ Corresponding author:jcharles@hortresearch.co.nz
}

\begin{abstract}
Laboratory bioassays confirmed the effectiveness of aerial applications of Foray 48B (Btk) against PAM over Auckland during 2002-2003. When neonate larvae were fed on Acacia mearnsii seedling foliage on the day of application (0 DA), 74-98\% of larvae died. Larval mortality then decreased with increasing time after the application of Btk, to ca 50\% at 6-7 DA and $30 \%$ at $12-13$ DA. In similar experiments, larval mortality was not affected by the height (1-5 $\mathrm{m}$ above ground level) from which leaves of sprayed mature A. mearnsii were collected, but did vary consistently between trees. Persistence of Btk on mature trees in the open was apparently lower than on seedlings kept in a shaded insectary. If an application resulted in high mean mortality across all trees at $0 \mathrm{DA}$, larvae typically died for 6-7 DA; whereas following an application that resulted in comparatively low mean mortality at 0 DA larvae usually died for only 4 DA.
\end{abstract}

Keywords: Teia anartoides, Btk, aerial application, bioassay.

\section{INTRODUCTION}

The painted apple moth (PAM), Teia anartoides (Lepidoptera: Lymantriidae), was discovered in a west Auckland suburb in May 1999. A second population was found in September 1999 in the more eastern suburb of Mt Wellington. The initial response was to spray the known larval populations and surrounding vegetation from the ground with insecticide, predominantly a synthetic pyrethroid (deltamethrin, as Decis Forte), and to remove and chip all of the infested trees. This strategy resulted in the eradication of the PAM population in the industrialised and relatively homogenous environment at Mt Wellington. However, PAM populations continued to increase in west Auckland suburbs, where dense host vegetation and steep topography prevented efficient tree removal or insecticide application. An alternative approach was required and aerial application of the biopesticide Bacillus thuringiensis var. kurstaki (Btk, as Foray 48B) was adopted by Government as a strategy to eradicate PAM. This paper describes trials to determine the duration of effectiveness against neonate PAM larvae of the Btk deposits on host tree foliage.

\section{Spraying operation}

\section{METHODS}

Approximately 35 aerial applications of Btk were made from January 2002 until May 2004. The first applications were made by helicopter to a limited area, but fixed wing aircraft subsequently covered a wider area, with supplementary helicopter spraying at some locations. The operational details to ensure that an effective dose of Btk was delivered to host-tree canopies (e.g. aircraft type, speed and height, nozzle type and droplet size, prevailing wind speed, etc.) are described elsewhere (Richardson et al. 2005).

\section{Determining larval mortality}

A standard bioassay was used to measure the toxicity to PAM of Btk deposits on Acacia mearnsii, which was the dominant and preferred host in the study areas. For each test, one pinnate leaf (ca $4 \mathrm{~cm}$ long) was removed, without prejudice, from sprayed seedling or tree canopy samples and placed in a $100 \mathrm{~mm} \times 130 \mathrm{~mm}$ minigrip $^{\mathrm{TM}}$ plastic bag. 
Three to five neonate PAM larvae (depending on the experiment) were added before sealing the bag. Each bag was then labelled with unique collection data and held at $20^{\circ} \mathrm{C}$ in a $16 \mathrm{~h}$ photoperiod, providing conditions suitable for rapid larval growth. PAM mortality was assessed under a binocular microscope after $96 \mathrm{~h}$. In bioassay development trials under these conditions, control mortality was usually zero. This bioassay was used in all assessments of Btk effectiveness.

\section{PAM mortality over time on leaves from potted seedlings}

Spray deposition was monitored by the spray contractors using 10-15 spray deposition cards placed along a linear transect at each of ca 12 sites within the spray zone. The sites were selected to reflect the range of natural and man-made obstacles to spraying (e.g. variable topography and power lines respectively) that might affect the effectiveness of the application. The number and size of the spray droplets on each card were calculated as a measure of the application efficiency at each site (Richardson et al. 2005). Experiments to determine how long Btk deposits remained effective at these sites were carried out after spray applications on 16 July, 23 August, 15-17 September, and 23 October 2002 (Sprays 7-10 respectively).

At each of 6-7 chosen sites, a small $(<1 \mathrm{~m}$ tall) potted $A$. mearnsii seedling was placed adjacent to each of 5 spray cards selected to be least shaded by neighbouring foliage. One seedling was selected as a spray-free control and was covered by a plastic bag before spraying began. The seedlings were retrieved after the spray deposits had dried and within $8 \mathrm{~h}$ of the completion of spraying, returned to HortResearch at Mt Albert, and maintained in an outdoor insectary. The roof and walls of the insectary were covered with a translucent synthetic mesh $\left(15 \times 15 \mathrm{mesh} / \mathrm{cm}^{2}\right)$ providing ca $50 \%$ shading, and the insectary itself was further shaded by large trees and buildings. The mean mortality of neonate PAM larvae exposed to foliage collected from the seedlings (using the standard bioassay described above) at day 0 and every ca 2 days for up to 13 days after the spray was applied was measured.

\section{PAM mortality over time on leaves collected from mature trees in situ}

Another estimate of the effectiveness of sprays against PAM over time was made by similar experiments on foliage from mature A. mearnsii trees in the spray zone.

An initial trial was carried out to compare the effectiveness of an application at different heights within the canopy of an individual tree. As soon as the foliage was dry after an aerial application (Spray 12, 2 December 2002), five foliage samples (each of 50-100 pinnate leaves) were collected from each of three layers of canopy ( $1 \mathrm{~m}, 3 \mathrm{~m}$ and $>5 \mathrm{~m}$ above ground level) from five different trees at each of two sprayed sites (Sites 1 and 2 ). The samples were placed individually into plastic bags marked with the tree number and canopy height. This procedure was repeated at 4,8 and ca 11 days after application. Larval mortalities within trees at different heights and over time were measured and compared using ANOVA.

Subsequently, five mature $A$. mearnsii trees ca 30-50 m apart were permanently marked at each of several additional sites with extensive $A$. mearnsii cover. The effectiveness of 13 aerial sprays (Sprays 15-27) spanning an 11-month period from 30 January to 11 November 2003, and including consecutive summer, winter and spring seasons, within these individual trees was then periodically measured at different sites. The bioassays provided PAM larvae with leaves collected from the 3 m-canopy layer, and mortality at 0 , and ca 4, 6, 8 and 11 days after application (DA) was measured. The actual day selected depended on weather conditions and other practicalities.

As well as monitoring the decline in mortality over time after application, the mortality of neonate larvae on foliage from each of the individual trees at two sites (1 and 3) was also measured after each of Sprays 15-27. Data were analysed using a randomised block design with 'spray number' as the block, 'tree' as the treatment, and the 'estimated percent PAM mortality/tree' as the response. Data from each site were analysed separately, first using a non-parametric approach (Friedman's test) and then, since there appeared to be no reasons for violation of the assumptions of independence and identically normal distribution of error terms, an analysis of variance. Percentage data were transformed before analysis. 


\section{RESULTS AND DISCUSSION \\ PAM mortality over time on leaves from potted seedlings}

Btk residues on leaves collected from seedlings on the day of application (0 DA) killed $74-98 \%$ of neonate PAM in the standard bioassays. Larval mortality subsequently decreased with time after the application, to ca 50\% at 6-7 DA and ca $30 \%$ at $12-13$ DA (Fig. 1). It was recognised that these experiments might not accurately reflect PAM mortality in the field because (1) the seedlings were so small that they effectively provided only a two-dimensional measure of the spray deposition at ground level, whereas PAM could be expected to feed within the entire canopy of mature A. mearnsii trees from 0 to $\geq 5 \mathrm{~m}$ above ground level; and (2) the seedlings in the insectary were cooler and less exposed to the Btk-destroying effects of sunlight. In addition, the experiments were carried out in winter and early spring when the light intensities were lower than in summer when PAM was most active.

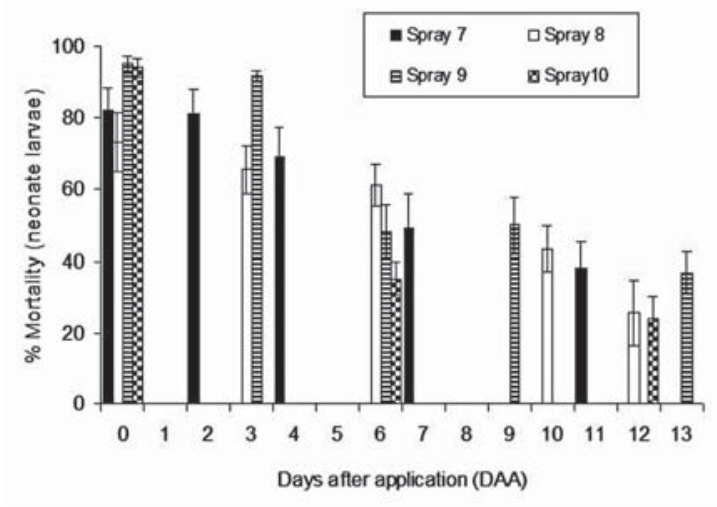

FIGURE 1: Mean ( \pm SE) mortality of PAM from 6-7 sites fed on A. mearnsii seedling foliage collected up to 13 days after Sprays 7-10 (July-October 2002).

\section{PAM mortality over time on leaves collected from mature trees 'in situ'}

For the Spray 12 application, there was no significant difference at either site 1 or 2 in PAM mortality when fed foliage from three different heights in the canopy, either at 0,4 or $8 \mathrm{DA}(\mathrm{P}=0.75)$. Mortality was significantly different between 0,4 and $8 \mathrm{DA}$ $(\mathrm{P}<0.001)$. Hence all subsequent bioassays used foliage sampled from the mid-canopy (at ca $3 \mathrm{~m}$ ) only.

The effectiveness of the applications was very variable, and the mean mortality/ spray/site at $0 \mathrm{DA}$ varied from 17.6 to $98.4 \%$. However, the mortality at $0 \mathrm{DA}$ from the various sprays was often rather consistent within sites, so that, for example, a selection of sprays shows that control at Site 4 (Fig. 2a) was usually better than at Site 3 (Fig. 2b). In addition, if a spray application provided a high PAM mortality at 0 DA, it usually resulted in relatively higher mortality over time after application. Finally, a comparison of Figures 1 and 3 illustrates that mortality over time decreased more rapidly on foliage from the open canopy than from the insectary, regardless of whether the sprays were applied in summer or winter. This is not surprising, since the sprayed foliage in the open canopy was exposed to greater light intensity and more realistic environmental conditions than that in the insectary. Nevertheless, the data show that an 'effective' application (i.e. one that resulted in high mortality at 0 DA at a site) usually also killed neonate PAM for at least 4-5 days. 

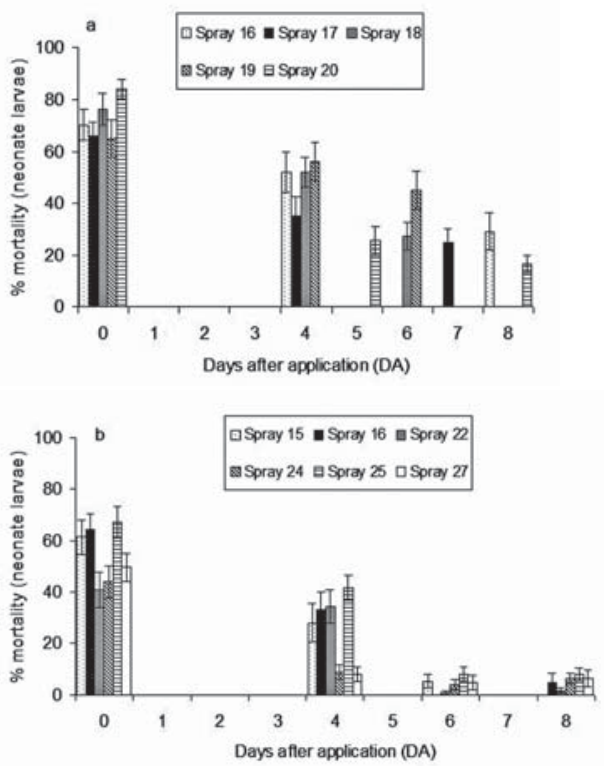

FIGURE 2: Mean ( \pm SE) mortality of PAM fed on leaves collected from mature A. mearnsii at (a) Site 4 and (b) Site 3 up to 8 days after each spray application

When data from Sprays 15-27 were combined, analysis showed that foliage from some of the marked trees at Sites 1 and 3 provided significantly higher neonate PAM mortality at 0 DA than others within each site, as illustrated in Table 1 . It is probable that these differences were associated with individual spatial or physical characteristics of the trees. The differences may have resulted from factors such as topography (e.g. hillsides, power lines, etc.), variable canopy shape causing turbulence, or other abiotic components of individual sprays (e.g. date specific interactions between wind speed, temperature and aircraft).

TABLE 1: Mean mortality (Sprays 15-27) at 0 DA of neonate PAM on individual trees at two sites.

\begin{tabular}{lccc}
\hline Location & Tree & \multicolumn{2}{c}{$\%$ mortality $^{1}$} \\
\hline Site 1 & A & 47.1 & ab \\
& B & 39.3 & a \\
& C & 68.2 & c \\
& D & 56.4 & abc \\
Site 3 & E & 62.2 & bc \\
& A & 68.6 & a \\
& B & 75.7 & a \\
& C & 40.5 & b \\
& D & 48.9 & b \\
& E & 43.2 & b
\end{tabular}

${ }^{1}$ Means followed by the same character within each site are not statistically different at $\mathrm{P}<0.05$. 


\section{CONCLUSIONS}

The overall consistency of the spray applications against PAM has been described elsewhere (Richardson et al. 2005), but these bioassays confirmed that aerial applications of Btk were effective against neonate PAM larvae. Larvae died even when fed on sprayed foliage that had been kept in a sheltered and shaded insectary for up to 13 days after the Btk application. More realistic experiments using sprayed foliage from mature A. mearnsii in the spray zones showed that there appeared to be inherent variability in the effectiveness of different applications. Larval mortality was not affected by the height from which the foliage was collected, but some trees appeared to receive consistently more or less Btk than others. In addition, larvae died only for 4-6 DA on foliage collected from these mature trees exposed to the natural Auckland environment. These data are consistent with other estimates of bioactivity of Bacillus thuringiensis that show residual activity on foliage of up to 14 days (for formulations containing UV protectants), with a half-life of spores or formulations of 4-10 days (Anon. 1999). Larval responses to Btk applications may differ for various reasons, including genetically inherited traits, a result of host plant/insect/insecticide interactions, or the abiotic environment.

In the experiments reported here climate, especially light intensity and rainfall, and site topography were almost certainly important variables. Further research is required, with greater control of these variables, to provide a more complete measure of the effective decay curve of the Btk deposits, especially within the 2-8 DA period.

\section{ACKNOWLEDGEMENTS}

This work was funded by MAF Biosecurity (now Biosecurity New Zealand). We thank Margie Rogers, AgriQuality, Auckland, for collecting foliage samples during this trial; Padmaja Ramankutty for assistance with statistical analysis; and Philippa Stevens, Brian Richardson and Colin Ferguson for constructive comments.

\section{REFERENCES}

Anon. 1999. Bacillus thuringiensis (Environmental health criteria; 217). World Health Organisation. http://www.who.int/ipcs/publications/ehc/en/EHC217.PDF (Accessed 11 May 2005).

Richardson B, Kay MK, Kimberley MO, Charles JG, Gresham BA 2005. Evaluating the benefits of dose-response bioassays during aerial pest eradication operations. New Zealand Plant Protection: 58: 17-23. 